\title{
Real Time ETEM Studies of the Nucleation and Growth of Carbon Nanotubes Utilizing Fe/Pt Catalyst on a Spherical $\mathrm{Al}_{2} \mathrm{O}_{3}$ Support
}

\author{
D.N. Zakharov, ${ }^{* * *}$ D.Y. Zemlyanov, ${ }^{*}$ A.U. Mane, ${ }^{* * *}$ J.W. Elam, ${ }^{* * *}$ F.H. Ribeiro, ${ }^{* * * *}$ and \\ E.A. Stach $* * * * * * *$ \\ * Birck Nanotechnology Center, Purdue University, West Lafayette, IN 47907 \\ ** School of Materials Engineering, Purdue University, West Lafayette, IN 47907 \\ *** Energy Systems Division, Argonne National Laboratory, Argonne, IL 60439 \\ **** School of Chemical Engineering, Purdue University, West Lafayette, IN 47907 \\ ***** Center for Functional Nanomaterials, Brookhaven National Laboratory, Upton, NY 11973
}

Iron is typically used as a catalyst for carbon nanotube (CNT) synthesis. It is known that the growth of CNTs implies the formation of a reduced phase of iron. However under certain conditions iron reduction can be hindered. On the other hand platinum is a noble metal known to facilitate the reduction of iron. Here we propose that there may be a synergetic action of platinum and iron: platinum can reduce iron and facilitate CNT growth.

In the present study we investigate two catalytic systems: bimetallic Fe/Pt and monometallic Fe. Catalyst metals were prepared by atomic layer deposition technique on spherical $\mathrm{Al}_{2} \mathrm{O}_{3}$ [1]. For $\mathrm{Fe} / \mathrm{Pt}$ sample metal loading were $7.7 \mathrm{wt} \%$ and $0.52 \mathrm{wt} \%$ for $\mathrm{Fe}$ and $\mathrm{Pt}$ respectively. The loading for pure Fe sample was $4.76 \mathrm{wt} \%$. X-ray photoelectron spectroscopy (XPS) was used to characterize the chemical state of freshly prepared catalysts. XPS demonstrated the presence of various platinum oxides whereas iron mainly exists as $\mathrm{Fe}^{3+}$. The XPS instrument was equipped with high-pressure / high-temperature catalytic cell which allows us to treat and to analyze a sample without exposure to the air. Annealing of freshly prepared samples at $300^{\circ} \mathrm{C}$ in $1.25 \% \mathrm{H}_{2}$ in Ar for an hour resulted in fully reduced $\mathrm{Pt}$ and partially reduced iron from $\mathrm{Fe}^{3+}$ to $\mathrm{Fe}^{2+}$. Reduced samples were transported from XPS chamber into environmental transmission electron microscope (ETEM) for further CNT growth at $600^{\circ} \mathrm{C}$ and $750^{\circ} \mathrm{C}$ respectively. The microscope base pressure was $4 \times 10^{-7}$ Torr. Before each growth a sample was heated to $100^{\circ} \mathrm{C}$ and kept at this temperature for an hour, and then heated up to the growth temperature. After thermal stabilization, $3.5 \times 10^{-5}$ Torr of acetylene was introduced inside microscope column. Real time images of nanotube nucleation and growth were obtained.

As shown in low magnification images, Fe/Pt catalyst (Fig.1a) demonstrates a smaller average particle size in comparison with the Fe catalyst (Fig.1c). This might be because bimetal Fe/Pt particles have different surface energy and binding energy with $\mathrm{Al}_{2} \mathrm{O}_{3}$ support in comparison to iron particles. In addition, the two samples show different CNTs morphology. Fe/Pt catalyst resulted in preferential formation of single- and few-walled CNTs while multi-walled CNTs were formed on Fe catalyst. This perfectly correlates with catalyst particle size distributions in both cases. High resolution TEM images (Fig.1b,d) demonstrate irregularities in CNTs structures grown at $600^{\circ} \mathrm{C}$. This suggests slow, pulse-like movement of catalyst particles, leaving behind caps in internal channels (Fig. 1b). At $750^{\circ} \mathrm{C}$ the performance of $\mathrm{Fe} / \mathrm{Pt}$ and Fe catalysts is completely different. In case of Fe/Pt catalyst the growth resulted in formation of single walled SWNTs. The tubes have smaller average diameter and much more regular wall structure in comparison with $600^{\circ} \mathrm{C}$ growth. Some of them form bundles. In contrast, no CNTs were formed on Fe catalyst in equivalent conditions. This is in our view is demonstration that adsorption/desorption of acetylene on catalyst 
surface is shifted towards desorption at a higher temperature. Our observations clearly demonstrate that the presence of platinum indeed promotes the growth of SWNTs through facilitating iron reduction and/or increasing of acetylene cracking/adsorption, and/or stabilizing smaller catalyst particles.

References

[1] W. Setthapun, et al., J. Phys. Chem. C, 114, 9758-771, 2009.
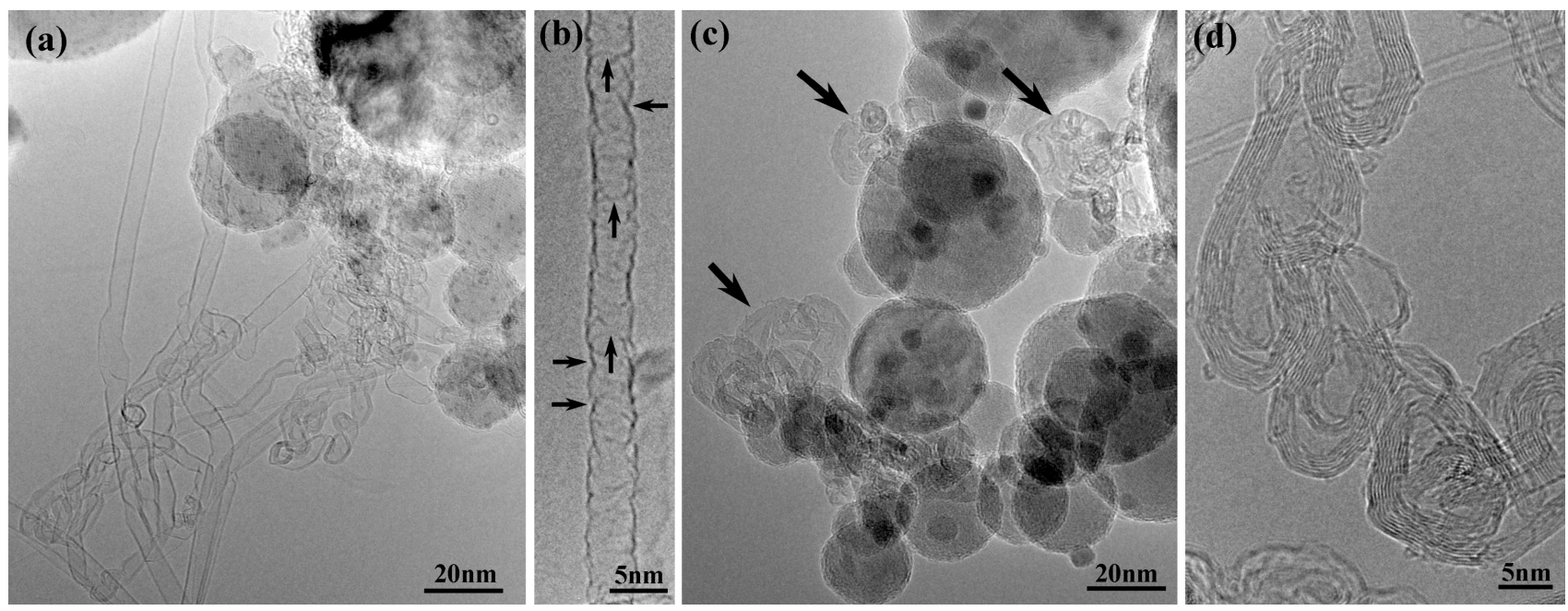

FIG. 1. CNTs growth via acetylene decomposition over Fe/Pt (a and b) and Fe (c and d) catalysts at $600^{\circ} \mathrm{C}$. Catalyst particles show stronger contrast with respect to spherical $\mathrm{Al}_{2} \mathrm{O}_{3}$. (a) Fe/Pt catalyst shows preferential growth of single and few walled carbon nanotubes. (b) Nanotubes demonstrate irregularities in walls structure and presence of caps in internal channel. Some are marked with horizontal and vertical arrows. (c) Fe catalyst shows growth of multi walled CNTs (black arrows). (d) HREM image shows highly defective structure with interlayer distance of $0.34 \mathrm{~nm}$.
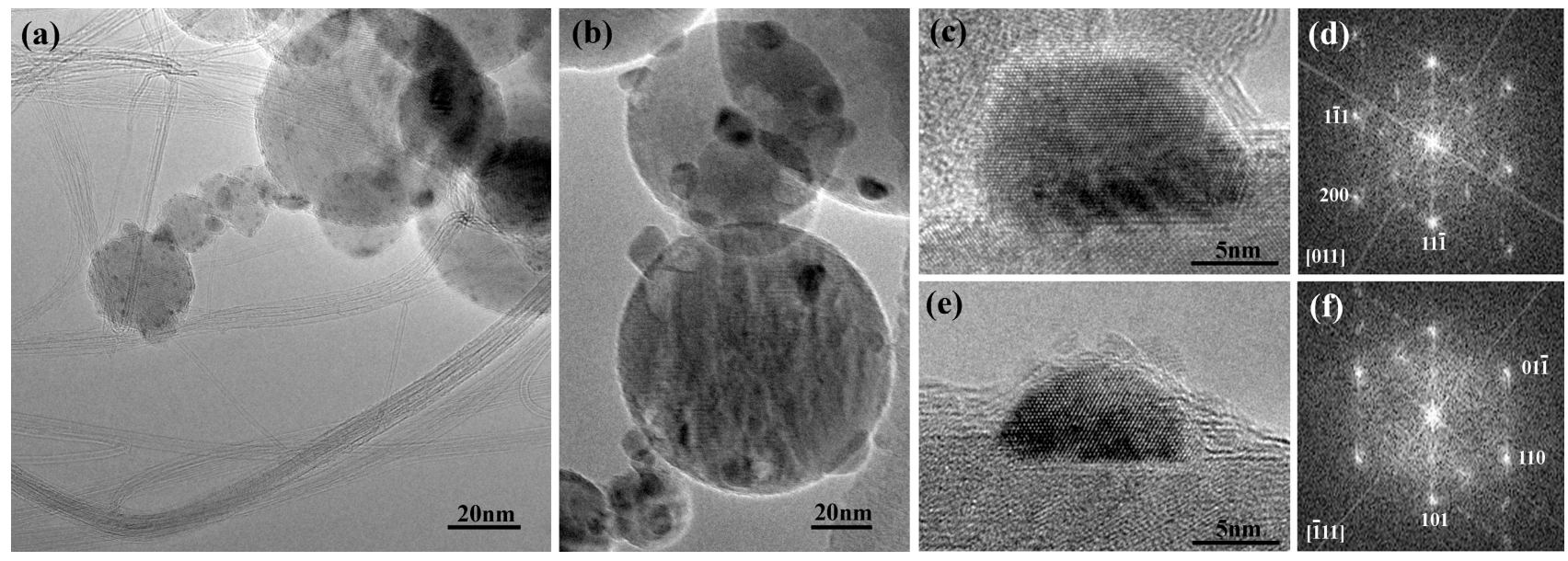

FIG. 2. CNTs growth via acetylene decomposition over $\mathrm{Fe} / \mathrm{Pt}(\mathrm{a})$ and $\mathrm{Fe}(\mathrm{b}-\mathrm{f})$ catalysts at $750^{0} \mathrm{C}$. Catalyst particles show stronger contrast with respect to spherical $\mathrm{Al}_{2} \mathrm{O}_{3}$. (a) $\mathrm{Fe} / \mathrm{Pt}$ catalyst resulted in formation of single walled nanotubes. Some nanotubes form bundles. (b) Iron catalyst showed absence of nanotubes formation. High resolution images reveal presence of face-centered cubic and body-centered cubic iron structures as indicated by (c) and (e) and corresponding fast Fourier transforms (d) and (f). 